\title{
PERSONAL RISK FACTORS FOR CARPAL TUNNEL SYNDROME IN FEMALE VISUAL DISPLAY UNIT WORKERS
}

\author{
MATTEO RICCÒ ${ }^{1}$, SILVIA CATTANI ${ }^{2}$, and CARLO SIGNORELLI ${ }^{3}$ \\ ${ }^{1}$ Provincial Agency for Health Services of the Autonomous Province of Trento, Trento, Italy \\ Department of Prevention, Occupational Health and Safety Unit \\ ${ }^{2}$ Parma University Hospital, Parma, Italy \\ School of Nursing Sciences, Department of Clinical Surgery, General Surgery and Surgical Therapy \\ ${ }^{3}$ Parma University, Parma, Italy \\ Department of Biomedical, Biotechnological and Translational Sciences (SBiBiT)
}

\begin{abstract}
Objectives: Carpal tunnel syndrome (CTS) is the most common nerve entrapment syndrome, which since the beginning of the seventies has been linked to the keyboard and visual display unit (VDU). The objective of this study was to investigate the prevalence and personal factors associated with CTS in female VDU workers in Italy. Material and Methods: Participants in this study were female adult subjects, working $\geq 20 \mathrm{~h} /$ week $(\mathrm{N}=631$, mean age 38.14 \pm 7.81 years, mean working age $12.9 \pm 7.24$ years). Signs and symptoms were collected during compulsory occupational medical surveillance. The binary logistic regression was used to estimate adjusted odds ratios for the factors of interest. Results: Diagnosis of CTS was reported in 48 cases $(7.6 \%, 11$ of them or $1.7 \%$ after a surgical correction) for the incidence of 5.94/1000 person-years. In general, signs and symptoms of CTS were associated with the following demographic factors: previous trauma of upper limb (adjusted odds ratio $\left(\mathrm{OR}_{\mathrm{a}}\right)=8.093,95 \%$ confidence interval $(\mathrm{CI})$ : 2.347-27.904), history ( $>5$ years) of oral contraceptives therapy/hormone replacement therapy $\left(\mathrm{OR}_{\mathrm{a}}=3.77,95 \% \mathrm{CI}: 1.701-8.354\right)$ and cervical spine signs/symptoms $\left(\mathrm{OR}_{\mathrm{a}}=4.565,95 \% \mathrm{CI}: 2.281-9.136\right)$. Conclusions: The prevalence of CTS was similar to the estimates for the general population of Italy. Among personal risk factors, hormone therapy, previous trauma of the upper limb and signs/symptoms of the cervical spine appeared to be associated with a higher risk of CTS syndrome. Eventually, the results reinforce interpretation of CTS in VDU workers as a work-related musculoskeletal disorder rather than a classical occupational disease. Int J Occup Med Environ Health 2016;29(6):927-936
\end{abstract}

Key words:

Carpal tunnel syndrome, Work-related musculoskeletal disorders, Nerve conduction studies, Computer office workers, Peripheral nervous system disease, Cumulative trauma disorder

\section{INTRODUCTION}

Carpal tunnel syndrome (CTS) is a symptomatic compression neuropathy of the median nerve at the level of the wrist, physiologically characterized by increased pressure within the carpal tunnel and a decreased function of the nerve at that level $[1,2]$. With the prevalence estimated between $7 \%$ and $18 \%$ of the adult population [3], CTS is the most common entrapment neuropathy of the

Received: August 26, 2015. Accepted: November 25, 2015.

Corresponding author: M. Riccò, Provincial Agency for Health Services of the Autonomous Province of Trento, Occupational Health and Safety Unit, Viale Verona SNC, C/O Centro Servizi Sanitari, 38123 Trento, Italy (e-mail: mricco2000@gmail.com). 
upper extremities [4,5]. Occupational (i.e., repetitive and forceful work such as gripping, vibrations) and non-occupational risk factors (i.e., female sex, age, obesity, diabetes, gynaecological surgery, menstrual problems/disorders and exercise levels) have been associated with CTS, suggesting a multifactorial aetiology [6-15].

The controversial association between CTS and visual display unit (VDU) use, suggested since the seventies of the last century, still remains an unsolved issue [16,17]. Recent reviews suggest weak or even insufficient evidence for a casual relationship between computer work and CTS [18-20], but these results may be undermined for several reasons.

First, research studies comparing computer workers with the general population or several occupational groups usually do not adjust their estimates for occupational risks in the control groups [16]. In other words, VDU workers may be compared with subjects previously or even still exposed to other occupational risk factors. Moreover, computers and information technology (IT) devices, such as smartphones and tablets, are extensively used during free and rest time for personal and leisure activities. Hence, a rigorous assessment of the exposure to VDU is even more arduous [16].

Second, until recently the definition of the exposure to VDU was difficult and erratic, as the use of computers and computer devices (i.e., mouse and keyboard) may be very heterogeneous and even a cut-off, based on the time spent at the VDU, has been irregularly applied [16-20].

Third, symptoms that are usually associated with CTS, such as numbness, tingling, burning or pain at the first digit and at wrist, are very common in the general population [1-5]. Also physical tests (such as Phalen's, reverse Phalen's, Tinel's and carpal compression test), even when combined, do not guarantee a reliable diagnosis without ultrasound and/or nervous conduction studies [1-3,21]: a large number of epidemiological studies on CTS in VDU workers are based on self-referred symptoms and the risk of CTS cases is over-reported. Conversely, several studies have attempted a more accurate case definition by drawing CTS cases form surgical or institutional (e.g., Occupational Health Insurance) registries [15,22,23]. Unfortunately, as the patients frequently fear that the surgical treatment may result in a reduced or even abolished fitness to work, in most cases CTS is surgically treated only in its later stages and/or only in more severe cases.

For similar reasons, CTS is also irregularly reported even in the countries where workers only need to demonstrate that they are suffering from a specific disease listed among presumptively work-associated diseases, that they have incurred the causal exposure or work tasks or that they have done jobs specified by this specific list in order to get a specific compensation (i.e., Italy, Belgium and France) [24]. In both cases, figures drawn from registries, even if more accurate in terms of the case definition, may be severely affected by underreporting.

Finally, studies on CTS in occupational medicine and, in particular, in VDU workers often lack an accurate evaluation of personal medical history. As CTS is a very frequent condition in adult females [3-5], for both anatomical and physiological reasons [1-5], with a very large array of well-established occupational and non-occupational risk factors [6-15], it should be interpreted as a "work related musculoskeletal disorder," i.e., an impairment of body structures associated with, rather than simply caused by, cumulative exposure to work and working environment over a long period of time [25]. In other words, not only occupational but also personal history influence in probabilistic terms natural history of CTS, both inducing and anticipating its clinical presentation $[1,2,16]$.

As CTS has become one of the most frequent causes of work compensation, both in Europe and in the United States, and due to the large and still increasing number of people working with computers, also a feeble excess of risk means that a high number of workers may then experience 
and denounce VDU-related CTS, with both personal and financial implications [26].

Therefore, the objective of this study was to investigate epidemiology of CTS in a well-defined study population of VDU female workers, and to assess whether personal risk factors may be associated with CTS diagnosis.

\section{MATERIAL AND METHODS}

\section{Study population}

The subjects were recruited from 4 companies, including public and private enterprises, as a part of a larger musculoskeletal survey performed during compulsory medical surveillance (Italian Legislative Decree No. 81 of April 9th 2008 [27]).

All the participants were female clerical workers performing data entry for at least $20 \mathrm{~h} /$ week during the previous 5 years. The study included only the subjects having a working history longer than 5 years, without any previous exposure to tasks requiring weight lifting, repetitive movements of the upper $\operatorname{limb}(\mathrm{s})$ or vibrations (either whole body and upper limb), with a personal history negative for either reactive or autoimmune arthritis.

Of the 1272 persons employed within the 4 organizations, $931(73.2 \%)$ fulfilled the inclusion criteria and, eventually, 631 (49.6\%) participated in the study and signed an informed consent.

\section{Clinical assessment}

A structured questionnaire was administered to all the studied workers in order to standardize data collection about demographic characteristics, work condition, pain condition and medical history. Among clinical data, history of previous traumas (i.e., either penetrating or closed injuries associated with at least 10 days of restricted/impaired movements of the arm) or surgical procedures of the upper limb were accurately collected. Data about drug consumption were also recalled, with particular attention to beta blockers and oral contraceptive therapy (OCT) (at least 5 years of cumulative use) and hormone replacement therapy (HRT); the latter variables were considered together for the purposes of the present analysis. Regular physical activity was defined following the World Health Organization (WHO) recommendation for 18-64 year-olds [28].

All the patients received a full medical assessment in order to obtain a complete musculoskeletal evaluation. Discomfort in the neck with or without radiation into the upper limb for at least 1 day during the preceding 12 months and/ or the presence of pain elicited by palpation of paravertebral muscles/spinal apophyses, and/or pain at active/passive mobilization of the neck identified the patients as positive at cervical spine clinical evaluation [29,30]. The patients reporting symptoms such as numbness, tingling, burning or pain in at least 1 of the 1st, 2nd or 3rd digit, palm or wrist pain and having a positive Phalen's test and/or positive reverse Phalen's test, and/or a positive Tinel's test, and/or positive carpal compression test, were considered clinically as potential cases of CTS and further evaluations with ultrasonography and/or nerve conduction study were performed [1,2]. Only patients where ultrasonography and/or nerve conduction defined a diagnosis of CTS were included in the study as cases.

\section{Statistical analysis}

Continuous variables were compared using the t-test, whereas the $\mathrm{Chi}^{2}$ test was applied to compare categorical variables. A univariate analysis was used to calculate the odds ratios (OR) and the $95 \%$ confidence intervals (CI).

A binary logistic regression model was then applied in order to calculate the correspondent adjusted odds ratios $\left(\mathrm{OR}_{\mathrm{a}}\right)$. The model included age and working age, and only variables statistically associated with CTS diagnosis in the univariate analysis.

All the statistical analyses were performed using SPSS version 22.0 (IBM Corp. released 2013, IBM SPSS Statistics for Macintosh, IBM Corp., USA). 
Table 1. Personal and demographic characteristics of the carpal tunnel syndrome (CTS) positive and negative cases*

\begin{tabular}{lccc}
\hline & \multicolumn{2}{c}{$\begin{array}{c}\text { Respondents } \\
\text { Variable }\end{array}$} & \multicolumn{2}{c}{$(\mathrm{M} \pm \mathrm{SD})$} \\
\cline { 2 - 3 } & $\begin{array}{c}\text { CTS positive } \\
(\mathrm{N}=48,7.6 \%)\end{array}$ & $\begin{array}{c}\text { CTS negative } \\
(\mathrm{N}=583,92.4 \%)\end{array}$ \\
\hline Age [years] & $41.10 \pm 7.82$ & $37.90 \pm 7.15$ & 0.003 \\
Working age [years] & $16.00 \pm 9.36$ & $12.65 \pm 7.63$ & 0.019 \\
Body mass index (BMI) $\left[\mathrm{kg} / \mathrm{m}^{2}\right]$ & $22.15 \pm 3.82$ & $22.07 \pm 3.55$ & 0.889 \\
\hline
\end{tabular}

* Continuous variables were analysed using the Student's t-test for unpaired data ( $\mathrm{p}<0.05$ was retained as statistically significant). $\mathrm{M}$ - mean; SD - standard deviation.

\section{Ethics}

The study was performed as part of the compulsory health assessment in the workplace (Italian Legislative Decree No. 81 of April 9th 2008 [27]): all the procedures were performed only in order to fully assess clinical status and fitness to work of the workers, and had to be performed regardless of the conduction of the study. Therefore, no preliminary evaluation by the Ethical Committee was reputed necessary. However, as clinical and personal data had to be collected and elaborated, all the participants gave their written consent, and the subjects who refused to give their consent were excluded from the study.

\section{RESULTS}

A CTS positive status was identified in 48 cases (7.6\%), for the estimated incidence of 5.94/1000 person-years. In 11 of them $(1.7 \%)$ a surgical correction was previously performed. Main demographic characteristics of the cases and controls are shown in Table 1. Carpal tunnel syndrome diagnosis was associated with the subjects of older age $(41.1 \pm 7.8$ years vs. $37.9 \pm 7.2$ years, $p=0.003)$ and reporting a longer working history $(16 \pm 9.4$ years vs. $12.7 \pm 7.63$ years, $p=0.019$ ).

In the univariate analysis (Table 2), the CTS positive subjects reported a positive personal history of OCT/ HRT $(\mathrm{OR}=5.236,95 \% \mathrm{CI}: 2.491-11.007)$ and beta blockers use $(\mathrm{OR}=2.831,95 \% \mathrm{CI}$ : $1.025-7.817)$ more frequently, whereas smoking history was similar both in the CTS positive and negative subjects (35.4\% vs. $31.6 \%$, $\mathrm{Chi}^{2}$ p-value $\left.=0.582\right)$. Musculoskeletal comorbidities, such as clinically confirmed cervical spine complaints $(\mathrm{OR}=4.881,95 \% \mathrm{CI}: 2.663-9.047)$, previous traumas $(\mathrm{OR}=10.4,95 \% \mathrm{CI}: 3.96-27.311)$ and history of surgical procedures $(\mathrm{OR}=10.232,95 \% \mathrm{CI}: 3.393-$ 30.859) of the upper limb, were more frequently identified in the CTS subjects. At the very same time, a regular sport or physical activity was associated with an insignificantly reduced risk of CTS diagnosis $(\mathrm{OR}=0.856,95 \%$ CI: 0.296-2.469).

Among systemic and metabolic disorders, both overweight (defined as body mass index (BMI) $\geq 25 \mathrm{~kg} / \mathrm{m}^{2}$ ) and obesity (BMI $\geq 30 \mathrm{~kg} / \mathrm{m}^{2}$ ) were not significantly associated with CTS diagnosis $(\mathrm{OR}=1.156,95 \%$ CI: $0.542-2.265$ and OR $=0.592,95 \%$ CI: 0.182-1.923, respectively). Diagnosis of diabetes mellitus (OR $=1.365,95 \%$ CI: 0.307 6.067) and hypothyroidism (OR $=1.357,95 \%$ CI: $0.515-$ 3.595) had similar prevalence in the CTS positive and negative cases.

The carpal tunnel syndrome positive subjects reported one or more pregnancies before the occurrence of clinical symptoms more frequently than the negative subjects (66.7\% vs. $53 \%)$, but the difference was not significant in the univariate analysis $\left(\mathrm{Chi}^{2}\right.$ test $\mathrm{p}$-value $=0.068$, OR $=1.773,95 \%$ CI: 0.952-3.303). 


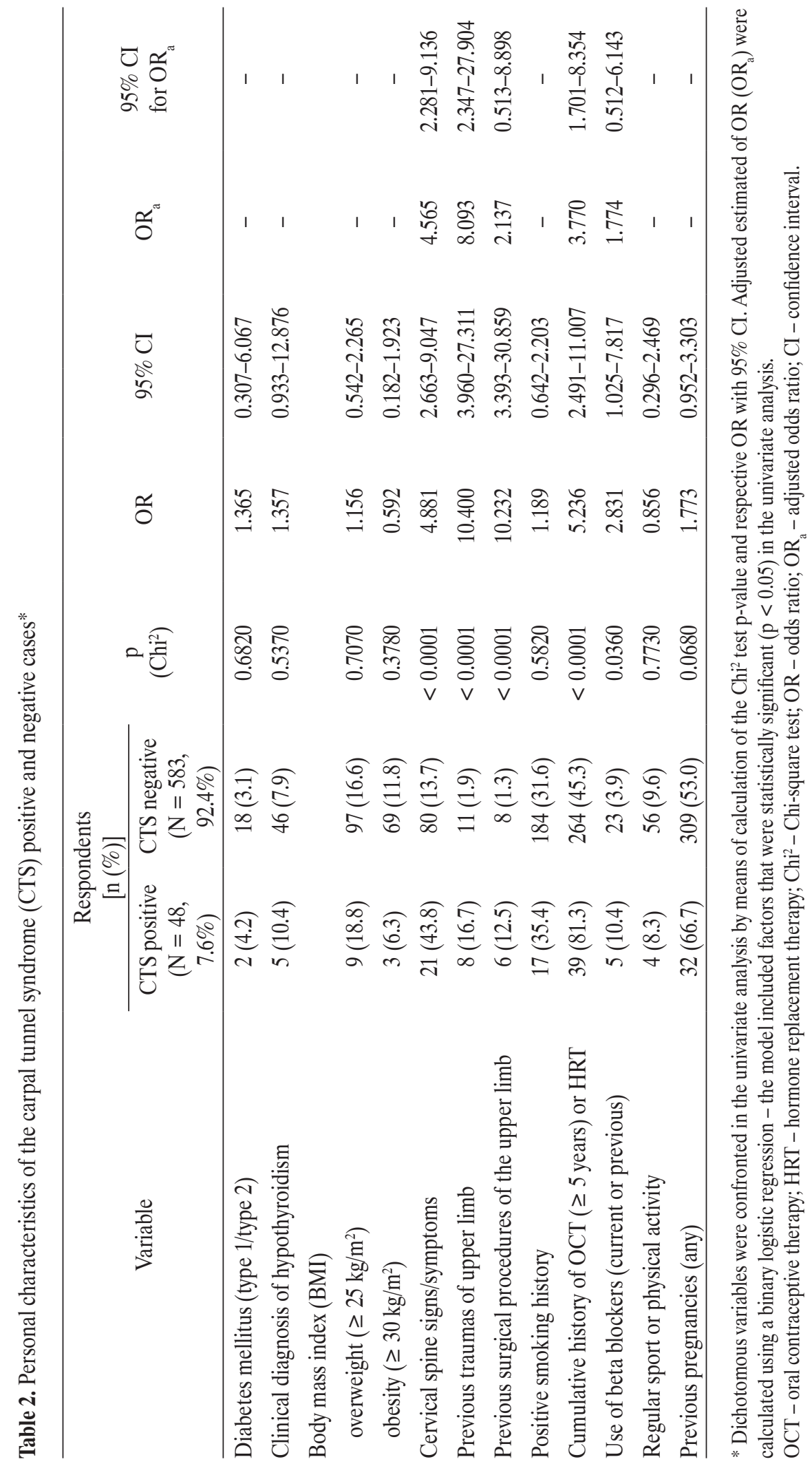


Eventually, the logistic regression was modelled including: age and working age, personal history of OCT/HRT, use of beta blockers, diagnosis of cervical spine complaints, personal history including previous traumas and previous surgery of the upper limb. Adjusted estimates for cervical spine complaints $\left(\mathrm{OR}_{\mathrm{a}}=4.565,95 \% \mathrm{CI}: 2.281-9.136\right)$, upper limb trauma $\left(\mathrm{OR}_{\mathrm{a}}=8.093,95 \% \mathrm{CI}: 2.347-27.904\right)$, OCT/HRT $\left(\mathrm{OR}_{\mathrm{a}}=3.77,95 \%\right.$ CI: 1.701-8.354) retained statistical significance.

\section{DISCUSSION}

The causal relationship between the CTS development and computer-related tasks has been disputed for several decades $[16,17]$. The use of mouse and keyboards requires a repetitive hand activity and non-neutral wrist postures, and both conditions have been identified as risk factors for CTS, but no decisive evidence has been still established [16,17,31]. In the last 30 years, CTS epidemiology in VDU workers has been repetitively described and even very large cohorts have been reported [16-20]. Unfortunately, several studies incorporated in the more recent and evidence based reviews have been largely criticised [16]. In this cross-sectional study, despite a relatively small sample size, selection criteria of the study population and the specific definition of CTS cases attempted to overcome some limitations of the previous studies.

First, the study population encompassed only the female sex subjects avoiding potential bias associated with the reduced incidence of CTS in males [1,2,16].

Second, only the subjects working with VDU for at least $20 \mathrm{~h} /$ week were included. Italian law concerning Health and Safety in the Workplace (Italian Legislative Decree No. 81 of April 9th 2008 [27]) enforces compulsory medical surveillance in clerical workers only for the subjects who actually work for at least $20 \mathrm{~h} /$ week, their effective exposure is accurately and periodically assessed by both an employer and an occupational physician. On the other hand, this selection criterion may be regarded as a limitation of the study: no quantitative evaluation of VDU and computer devices was actually provided, and despite all the subjects performed the same tasks (i.e., data entry), the population remains heterogeneous in terms of repetitive hand activity and non-neutral wrist postures. A more accurate evaluation of the exposure may be performed in the future - the authors thought about recording effective computer activity, in particular keyboard strokes and mouse movements [32]. Unfortunately, all these elements may be interpreted controversially, and also data collection may be interpreted as not compliant with labour regulations regarding privacy and monitoring of the workers (e.g., the current Italian Labour Law, Law No. 300 of May 20th 1970) [33].

Third, the subjects with a personal occupational history including exposure to occupational risk factors, such as: vibrations (either arm or whole-body), vibrating tools, weight lifting, repetitive and forceful movements, were excluded from the study. Therefore, the associated with the cut-off inclusion criterion, i.e., at least 5 years of previous working history as a VDU worker, should rule out occupational risk factors not related to the computer use in the pathogenesis of CTS.

Finally, as CTS is listed among presumptively work associated diseases and Italian law enforces an early identification of such disorders, in all the cases where clinical symptoms were associated with suggestive results of the physical examination, medical surveillance was complemented by diagnostic tests (performed at employers' expenses) that guarantee a more accurate diagnosis of the disorder. In our population, CTS prevalence was $7.6 \%$, with the incidence of 5.94/1000 person-year - this incidence is quite similar to that reported in the general population of $\mathrm{Si}$ ena during the decade 1991-1998 [34] - a study which, similarly to our study, based CTS diagnosis on nerve conduction studies. Among the studies performed in occupational settings, our figures are similar to those reported 
by Stevens et al. in 2002 [35], slightly higher than those reported by Andersen et al. in their larger, 1-year follow-up study (1.4-4.8\%) based on a screening questionnaire and a clinical interview [36], and similar to those reported by Eleftheriou et al. in 461 Greek employees from a governmental data entry and processing unit [32], with a broader case definition.

As expected, the CTS cases were older and reported a longer working history than the non-CTS cases [15,36-38]. Obviously the 2 variables are not truly independent and, as older age groups are strongly associated with an increased risk for CTS diagnosis, a cautionary interpretation is necessary.

Interestingly enough, conditions frequently reported in CTS, such as: overweight and obesity, but also previous pregnancies and metabolic diseases (i.e., diabetes and hypothyroidism), in our study were not associated with a higher risk of CTS, even in the univariate analysis. On the other hand, history of OCT/HRT and beta blockers use was reported more frequently by the CTS cases than the negative cases, and the multivariate analysis confirmed an increased risk of CTS in OCT/HRT users $\left(\mathrm{OR}_{\mathrm{a}}=3.77,95 \% \mathrm{CI}: 1.701-8.354\right)$. This association was consistent with previous evidence, as any factor influencing hormonal status, either exogenous (including oral contraceptives and hormone replacement therapy) or endogenous (i.e., menstrual problems such as amenorrhea, heavy periods, dysmenorrhea, but also menopause) was previously identified as a risk factor for CTS [14,39].

A previous or coexisting diagnosis of musculoskeletal disorders has been frequently reported in CTS patients [31,40], but the appearance of CTS after the upper limb trauma and/or upper limb surgery has been rarely evaluated and usually interpreted as a rare issue $[15,41,42]$. In general, the studies on CTS and trauma have focused on short term complications of trauma involving a pressure increase in the carpal tunnel [42]. As anything that irritates or compresses the median nerve in the carpal tunnel space can lead to carpal tunnel syndrome, these findings hint for a more accurate recall of previous personal history in CTS patients. Similarly, our report identified a very high prevalence of neck involvement in the CTS patients $\left(\mathrm{OR}_{\mathrm{a}}=4.565,95 \% \mathrm{CI}: 2.281-9.136\right)$. In fact, there is some evidence suggesting a diffuse involvement of the cervical spine in at least some patients with CTS [43,44], but there is no concluding evidence whether cervical complaints are a consequence or causative factor of CTS.

\section{CONCLUSIONS}

In our study, encompassing 631 females working with VDU and performing data entry activities, both prevalence and incidence of CTS were roughly similar to those from the previous reports on the general population of Italy, simultaneously supporting a limited effect of computer work on the natural history of CTS.

Also personal risk factors such as OCT/HRT and previous history of traumas at the upper limb were associated with an increased risk for CTS. As the CTS patients also exhibited a high risk for cervical spine complaints, our results suggest that personal risk factors rather than occupational exposures may be involved in the CTS pathogenesis.

The latter point is of particular interest, and future research will point out whether cervical involvement in CTS is a consequence or rather a causative factor of CTS and related symptoms. In summary, these results reinforce the interpretation of CTS as a work related musculoskeletal disorders rather than as a "classical" occupational disease, at least in the subjects whose occupational exposures are associated with VDU use in the workplace.

\section{REFERENCES}

1. Lawson IJ, Burke F, McGeoch KL, Nilsson T, Proud G. Handarm vibration syndromes. In: Baxter PJ, Aw T-C, Cockcroft A, Durrington P, Harrington JM, editors. Hunters disease of occupations. 10th ed. London: CRC Press; 2010. p. 498-512, http://dx.doi.org/10.1201/b13467-61. 
2. American Academy of Orthopaedic Surgeons Work Group Panel. Clinical practice guideline on the diagnosis of carpal tunnel syndrome. 1st ed. Rosemont (IL): The Academy; 2007.

3. Ferry S, Pritchard T, Keenan J, Croft P, Silman AJ. Estimating the prevalence of delayed median nerve conduction in the general population. Br J Rheumatol. 1998;37:630-5, http://dx.doi.org/10.1093/rheumatology/37.6.630.

4. Ghasemi-Rad M, Nosair E, Vegh A, Mohammadi A, Akkad A, Lesha E, et al. A handy review of carpal tunnel syndrome: From anatomy to diagnosis and treatment. World J Radiol. 2014;6:284-300, http://dx.doi.org/10.4329/wjr. v6.i6.284.

5. Bickel KD. Carpal tunnel syndrome. J Hand Surg Am. 2010;35:147-52, http://dx.doi.org/10.1016/j.jhsa.2009.11.003.

6. Viikari-Juntura E, Silverstein B. Role of physical load factors in carpal tunnel syndrome. Scand J Work Environ Health. 1999;25:163-85, http://dx.doi.org/10.5271/ sjweh.423.

7. Silverstein BA, Fine LJ, Armstrong TJ. Occupational factors and carpal tunnel syndrome. Am J Ind Med. 1987;11:343-58, http://dx.doi.org/10.1002/ajim.4700110310.

8. Olney RK. Carpal tunnel syndrome: Complex issues with a "simple" condition. Neurology. 2001;56:1431-2.

9. Goodson JT, DeBerard MS, Wheeler AJ, Colledge AL. Occupational and biopsychosocial risk factors for carpal tunnel syndrome. J Occup Environ Med. 2014;56:965-72, http:// dx.doi.org/10.1097/JOM.0000000000000202.

10. Harris-Adamson C, Eisen EA, Kapellusch J, Garg A, Hegmann KT, Thiese MS, et al. Biomechanical risk factors for carpal tunnel syndrome: A pooled study of 2474 workers. Occup Environ Med. 2015;72:33-41, http://dx.doi.org/10. 1136/oemed-2014-102378.

11. Harris-Adamson C, Eisen EA, Dale AM, Evanoff B, Hegmann KT, Thiese MS, et al. Personal and workplace psychosocial risk factors for carpal tunnel syndrome: A pooled study cohort. Occup Environ Med. 2013;70:529-37, http:// dx.doi.org/10.1136/oemed-2013-101365.
12. Burt S, Crombie K, Jin Y, Wurzelbacher S, Ramsey J, Deddens J. Workplace and individual risk factors for carpal tunnel syndrome. Occup Environ Med. 2011;68:928-33, http:// dx.doi.org/10.1136/oem.2010.063677.

13. Solomon DH, Katz JN, Bohn R, Mogun H, Avorn J. Nonoccupational risk factors for carpal tunnel syndrome. J Gen Intern Med. 1999 Apr 15;14:310-4, http://dx.doi.org/10.1046/ j.1525-1497.1999.00340.x.

14. Ferry S, Hannaford P, Warskyj M, Lewis M, Croft P. Carpal tunnel syndrome: A nested case-control study of risk factors in women. Am J Epidemiol. 2000;151:566-74, http://dx.doi. org/10.1093/oxfordjournals.aje.a010244.

15. Mattioli S, Baldasseroni A, Bovenzi M, Curti S, Cooke RM, Campo $\mathrm{G}$, et al. Risk factors for operated carpal tunnel syndrome: A multicenter population-based case-control study. BMC Public Health. 2009;9:343, http://dx.doi. org/10.1186/1471-2458-9-343.

16. Shiri R, Falah-Hassani K. Computer use and carpal tunnel syndrome: A meta-analysis. J Neurol Sci. 2015;349:15-9, http://dx.doi.org/10.1016/j.jns.2014.12.037.

17. Andersen JH, Fallentin N, Thomsen JF, Mikkelsen S. Risk factors for neck and upper extremity disorders among computers users and the effect of interventions: An overview of systematic reviews. PLoS One. 2011;6:e19691, http://dx.doi. org/10.1371/journal.pone.0019691.

18. IJmker S, Huysmans MA, van der Beek AJ, Knol DL, van Mechelen W, Bongers PM, et al. Software-recorded and self-reported duration of computer use in relation to the onset of severe arm-wrist-hand pain and neck-shoulder pain. Occup Environ Med. 2011 Jul;68:502-9, http://dx.doi.org/ 10.1136/oem.2010.056267.

19. Andersen JH, Harhoff M, Grimstrup S, Vilstrup I, Lassen CF, Brandt LPA, et al. Computer mouse use predicts acute pain but not prolonged or chronic pain in the neck and shoulder. Occup Environ Med. 2008;65:126-31, http:// dx.doi.org/10.1136/oem.2007.033506.

20. Mediouni Z, de Roquemaurel A, Dumontier C, Becour B, Garrabe $\mathrm{H}$, Roquelaure $\mathrm{Y}$, et al. Is carpal tunnel syndrome 
related to computer exposure at work? A review and metaanalysis. J Occup Environ Med. 2014;56:204-8, http://dx.doi. org/10.1097/JOM.0000000000000080.

21. Homan MM, Franzblau A, Werner RA, Albers JW, Armstrong TJ, Bromberg MB. Agreement between symptom surveys, physical examination procedures and electrodiagnostic findings for the carpal tunnel syndrome. Scand J Work Environ Health. 1999;25:115-24, http://dx.doi.org/10.5271/sjweh.413.

22. Rigouin P, Ha C, Bodin J, le Manac'h AP, Descatha A, Goldberg M, et al. Organizational and psychosocial risk factors for carpal tunnel syndrome: A cross-sectional study of French workers. Int Arch Occup Environ Health. 2013;87:147-54, http://dx.doi.org/10.1007/s00420-013-0846-0.

23. Curti SC, Mattioli, Baldasseroni, Bovenzi, Bonfiglioli, Violante. Occupational and non-occupational risk factors for surgically treated carpal tunnel syndrome: Preliminary results of a multicentre population-based case-control study [abstract]. Occup Environ Med. 2013;70(S1):A86, http:// dx.doi.org/10.1136/oemed-2013-101717.253.

24. Ladou J. The European influence on workers' compensation reform in the United States. Environ Health. 2011;10:103, http://dx.doi.org/10.1186/1476-069X-10-103.

25. European Agency for Safety and Health at Work. Workrelated musculoskeletal disorders: Prevention report. Luxembourg: Office for Official Publications of the European Communities; 2008.

26. Huysmans MA, IJmker S, Blatter BM, Knol DL, van Mechelen W, Bongers PM, et al. The relative contribution of work exposure, leisure time exposure, and individual characteristics in the onset of arm-wrist-hand and neck-shoulder symptoms among office workers. Int Arch Occup Environ Health. 2012;85:651-66, http://dx.doi.org/10.1007/s00420-011-0717-5.

27. [The Act No. 81 of 9 April 2008 on health and safety in the workplaces. J Laws (GU) 2008, No. 101, ordinary suppl. No. 108]. Italian.

28. World Health Organization. Global recommendations on physical activity for health. Geneva: World Health Organization Press; 2010.
29. Colombini D, Occhipinti E, Menoni O, Bonaiuti D, Cantoni S, Molteni G, et al. [Diseases of the dorsal-lumbar spine and manual handling of loads: Guidelines for fitness assessment]. Med Lav. 1993;84(5):416-32. Italian.

30. Violante FS, Bonfiglioli R, Mattioli S, Baldasseroni A, Baratti A, Bazzini G, et al. [Prevention of diseases associated to patient handling: Guidelines]. Pavia: Società Italiana di Medicina del Lavoro ed Igiene Industriale; 2008. Italian.

31. Burt S, Crombie K, Jin Y, Wurzelbacher S, Ramsey J, Deddens J. Workplace and individual risk factors for carpal tunnel syndrome. Occup Environ Med. 2011;68:928-33, http:// dx.doi.org/10.1136/oem.2010.063677.

32. Eleftheriou A, Rachiotis G, Varitimidis SE, Koutis C, Malizos KN, Hadjichristodoulou C. Cumulative keyboard strokes: A possible risk factor for carpal tunnel syndrome. J Occup Med Toxicol. 2012;7(1):16, http://dx.doi. org/10.1186/1745-6673-7-16.

33. [The Act No. 300 of 20 May 1970 on the labour code. J Laws (GU) 1970, No. 131]. Italian.

34. Mondelli M, Giannini F, Giacchi M. Carpal tunnel syndrome incidence in a general population. Neurology. 2002;58:28994, http://dx.doi.org/10.1212/WNL.58.2.289.

35. Stevens JC, Witt JC, Smith BE, Wearer AL. The frequency of carpal tunnel syndrome in computer users at a medical facility. Neurology. 2002;56:1568-70, http://dx.doi.org/10.1212/ WNL.56.11.1568.

36. Andersen JH, Thomsen JF, Overgaard E, Lassen CF, Brandt LP, Vilstrup I, et al. Computer use and carpal tunnel syndrome. A 1-year follow-up study. JAMA. 2003;289: 2963-9, http://dx.doi.org/10.1001/jama.289.22.2963.

37. Roquelaure Y, Ha C, Nicolas G, Pelier-Cady M-C, Mariot $\mathrm{C}$, Descatha $\mathrm{A}$, et al. Attributable risk of carpal tunnel syndrome according to industry and occupation in a general population. Arthritis Rheum. 2008;59:1341-8, http://dx.doi. org/10.1002/art.24002.

38. Roquelaure Y, Ha C, Pelier-Cady M-C, Nicolas G, Descatha $\mathrm{A}$, Leclerc $\mathrm{A}$, et al. Work increases the incidence of 
carpal tunnel syndrome in the general population. Muscle Nerve. 2008;37:477-82, http://dx.doi.org/10.1002/mus.20952.

39. Albani G, Priano L, Campanelli L, Pignatti R, Liuzzi A, Galotti P, et al. Carpal tunnel syndrome and oral contraceptive drugs: Risk or protective factor? J Peripher Nerv Syst. 2003;8:207-8, http://dx.doi.org/10.1111/j.10859489.2003.03026.x.

40. Nordstrom DL, Vierkant RA, DeStefano F, Layde PM. Risk factors for carpal tunnel syndrome in a general population. Occup Environ Med. 1997;54:734-40, http://dx.doi. org/10.1136/oem.54.10.734.

41. Niver GE, Ilyas AM. Carpal tunnel syndrome after distal radius fracture. Orthop Clin North Am. 2012;43:521-7, http:// dx.doi.org/10.1016/j.ocl.2012.07.021.
42. Heim D, Stricker U, Rohrer G. [Carpal tunnel syndrome after trauma]. Swiss Surg. 2002;8:15-20. German.

43. De-la-Llave-Rincòn AI, Fernandez-de-las-Peñas CF, Laguarta-Val S, Ortega-Santiago R, Palacios-Ceña D, Martinez-Perez A. Women with carpal tunnel syndrome show restricted cervical range of motion. J Orthop Sports Phys Thera. 2011;41:305-10, http://dx.doi.org/10.2519/jospt. 2011.3536.

44. Reading I, Walker-Bone K, Palmer KT, Cooper C, Coggon D. Anatomic distribution of sensory symptoms in the hand and their relation to neck pain, psychosocial variables, and occupational activities. Am J Epidemiol. 2003;157: 524-30, http://dx.doi.org/10.1093/aje/kwf225.

This work is available in Open Access model and licensed under a Creative Commons Attribution-NonCommercial 3.0 Poland License - http://creativecommons.org/ licenses/by-nc/3.0/pl/deed.en. 